\title{
Osseous choristoma presenting as a cold solitary thyroid nodule
}

\author{
S.N. Banerjee, N.Ananthakrishnan, A.J. Veliath and C. Ratnakar \\ Departments of Surgery and Pathology, Jawaharlal Institute of Postgraduate Medical Education and Research, \\ Pondicherry 605006, India.
}

\begin{abstract}
Summary: A hitherto undescribed case of an osseous choristoma of the thyroid presenting as a single cold nodule is presented. The possible origin of the lesion is discussed.
\end{abstract}

\section{Introduction}

Adenomas, nodular goitre and carcinomas are the commonest causes of single thyroid nodules, the probability of malignancy being higher if the nodule is nonfunctioning on an ${ }^{131} \mathrm{I}$ scan.

We present here a rare, hitherto undescribed cause of a solitary thyroid nodule which simulated a malignancy.

\section{Case report}

A 45 year old woman presented with a swelling in the region of the thyroid, of one year's duration, with no apparent change in size over the period. There were no symptoms of thyroid dysfunction or pressure effects. Clinical examination revealed a hard $2 \times 2 \mathrm{~cm}$ solitary nodule of the entire right lobe of the thyroid. The left lobe was not palpable and there were no palpable lymph nodes in the neck.

A radioactive iodine $\left({ }^{131} \mathrm{I}\right)$ scan revealed the nodule to be cold, with a normal uptake in the left lobe. An ultrasound examination showed that the nodule was solid. Indirect laryngoscopy revealed normal movement of the vocal cords.

A clinical diagnosis of a solitary thyroid nodule, probably malignant, was made. At operation, there was a $2 \times 2 \mathrm{~cm}$ hard nodule involving the right lobe. The left lobe appeared normal. A right hemithyroidectomy was performed.

Histologically a diagnosis of osseous choristoma was made (Figure 1). There was no evidence of malignancy.

Correspondence: S.N. Banerjee, M.S., Department of Surgery, JIPMER, Pondicherry 605006, India.

Accepted: 30 May 1986

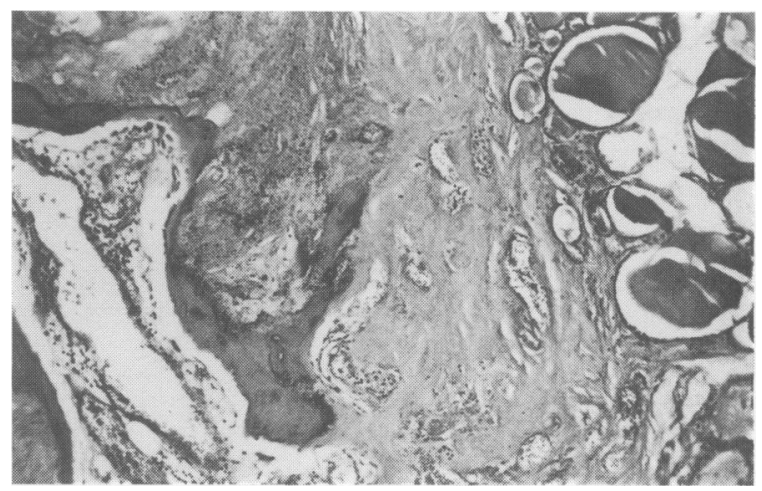

Figure 1 Photomicrograph of excised right lobe of thyroid showing the osseous choristoma and the normal thyroid acini ( $\mathrm{H}$ and $\mathrm{E} \times 165)$.

\section{Discussion}

Most large series of solitary nodules of the thyroid have found an adenoma, carcinoma or a cyst as the commonest cause (Hoffman et al., 1972; Brown \& Kantounis, 1975; Bhansali, 1982). Rare causes of solitary nodules in the thyroid include an autonomous nodule, lymphoma, thyroiditis, congenital cyst, haematoma (Hoffman et al., 1972), fibrosarcoma (Brown \& Kantounis, 1975) and secondaries. The present case of an osseous choristoma adds to this list of rare causes.

The term choristoma has been applied to microscopically normal tissues that are present in abnormal locations, as opposed to hamartomas. Osseous choristomas of the oral cavity have been reported (Krolls et al., 1971; Main, 1984), more commonly in female patients. The vast majority of these lesions were on the dorsum of the tongue close to the region of the 
foramen caecum or just posterior to the circumvallate papillae. Though their aetiology is still unknown, it is presumed that they develop from persistent skeletal remnants of the second and third branchial arches (Main, 1984). Since the thyroid develops from the region of the foramen caecum of the tongue, an osseous choristoma of the thyroid may have a similar

\section{References}

BHANSALI, S.K. (1982). Solitary nodule in the thyroid gland: experiences with 600 cases. Indian Journal of Surgery, 44, 547.

BROWN, C.L. \& KANTOUNIS, S. (1975). The thyroid nodule. American Journal of Surgery, 129, 532.

HOFFMAN, G.L., THOMPSON, N.W. \& HEFFRON, C. (1972). aetiology. Alternatively, metaplasia or dystrophic bone induction, secondary to inflammation, have been suggested (Main, 1984). However, this is considered less likely.

The importance of this lesion lies in its presentation as a hard, cold, single thyroid nodule, clinically simulating a carcinoma of the thyroid gland.

The solitary thyroid nodule. Archives of Surgery, 105, 379. KROLLS, S.O., JACOWAY, J.R. \& ALEXANDER, W.N. (1971). Osseous choristomas (osteomas) of intraoral soft tissues. Oral Surgery, Oral Medicine \& Oral Pathology, 32, 588. MAIN, D.M.G. (1984). Osseous polyp of the tongue: osteoma or choristoma. British Dental Journal, 156, 285. 